thoracic. Each commissure gives off a nerve three and one-half millimetres from the ganglion, going caudad. The distance of these nerves from the ganglion varies however (fig. II. 0 ).

5. The vagus nerve. - The vagus nerve of Corydalus cornutus arises as two nerves from the crura cerebri, dorsad of the labial nerves (fig. IV. 9). These nerves pass cephalo-mesad, forming two arches, and unite in a ganglion on the median line dorsad of the palate. This ganglion (fig. I. 2, fig. IV. 2) is sometimes called the frontal ganglion, and is immediately cephalad of the supra-oesophageal ganglion. The vagus nerve departs from the caudad part of the ganglion, passes caudad between the aorta and the oesophagus, and continues on the median line until it reaches a point two millimetres caudad of the frontal ganglion (fig. IV. 9). Here it enters another ganglion smaller than the frontal ganglion. This ganglion is also situated on the median line between the aorta and the oesophagus. Two nerves depart from this ganglion, going laterocaudad to the sides of the oesophagus (fig. I. 8, fig. IV. o). They continue their course caudad until they reach the pro-ventriculus, where they divide into many branches.

The vagus nerve gives branches to the aorta in the head, and numerous nerves are continually given off to the oesophagus.

\title{
SEXUAL CHARACTERS IN THE CHRYSALIDS OF GRAPTA INTERROGATIONIS.
}

BY MARY ESTHER MURTFELDT, KIRKWOOD, MO.

The publication in Psyche for November-December I883, v. 4, p. Iо3Io6, of the full text of Mr. Lintner's interesting paper on "A new sexual character in the pupae of some lepidoptera," reminds me of an observation which I made last summer on the chrysalids of Grapta interrogationis.

Desirous of obtaining fresh specimens of this species, I placed about a dozen clm-feeding larvae in a rearing cage, from which, in due time, I sbtained eleven chrysalids. These were, in respect to color and ornamentation, of two distinct sorts. The larger proportion were of a dull, pale fuscous with darker brown lateral stripes, dots and markings, without a trace of metallic ornamentation, while four were much paler in general color, inclining to golden brown, each ornamented with the eight brilliant, pale-golden, papillose dorsal spots by which this chrysalis is usually characterized. From each of the pale and gilded chrysalids emerged a female, while the seven dark and unornamented ones gave forth males exclusively. This observation may be a mere corroboration of a well known fact concerning the sexual characters of the species, but if so I have not met with it, or it has entirely escaped my memory. 


\section{Explanation of Plate 2.}

Fig. I. Dorsal view of the head, showing the supra-oesophageal ganglia and nerves. $\times 6$.

I, Supra-oesophageal ganglia. 2, Frontal ganglion. 3, Clypeo-labral nerve. 4 , Antennal nerve. $a$, Sensor branch. $b$, Motor branch. $c$, Integumentary branch. 5, Optic nerves. 6, Oesophagus. 7, Aorta. 8, Vagus nerve. 9, Antennal muscles.

Fig. II. Ventral view of the head, showing the sub-oesophageal ganglion and nerves. $\times 6$.

I, Sub-oesophageal ganglion. 2, Gustatory nerve. 3, Labial nerve. 4, Mandibular nerve. 5, Maxillary nerve. 6, 7,8, Unnamed nerves. 9, Commissure. o, Commissural nerve.

Fig. III. The maxilla with its three large nerves. Nerve $d$, fig. II, not shown. $\times 7$.

Fig. IV. Ventral aspect of the supra-oesophageal ganglia, the crura cerebri turned cephalad. $\times 15$.

I, Supra-oesophageal ganglia. 2, Frontal ganglion. 3, Crura cerebri. 4, Tracheae. 5, Aorta. 6, Optic nerves. 7, Antennal nerve. 8, Clypeo-labral nerve. 9, Vagus nerve. o, Vagus nerve.

Fig. v. The mandible with its nerves. $\times 7$.

Fig. vi. The separation and dissection of the seven optic nerves. $\times$ Io. I, Optic trunk of nerves. 2, Optic nerve. 3, Neurilemma.

Fig. vil. Showing principally the cross-nerve of the crura cerebri, the cephalad extremity of the sub-oesophageal ganglion having been dissected away. $\times$ I 2 .

I, The sub-oesophageal ganglion. 2, Crura cerebri. 3, Cross nerve. 4, Commissure. 

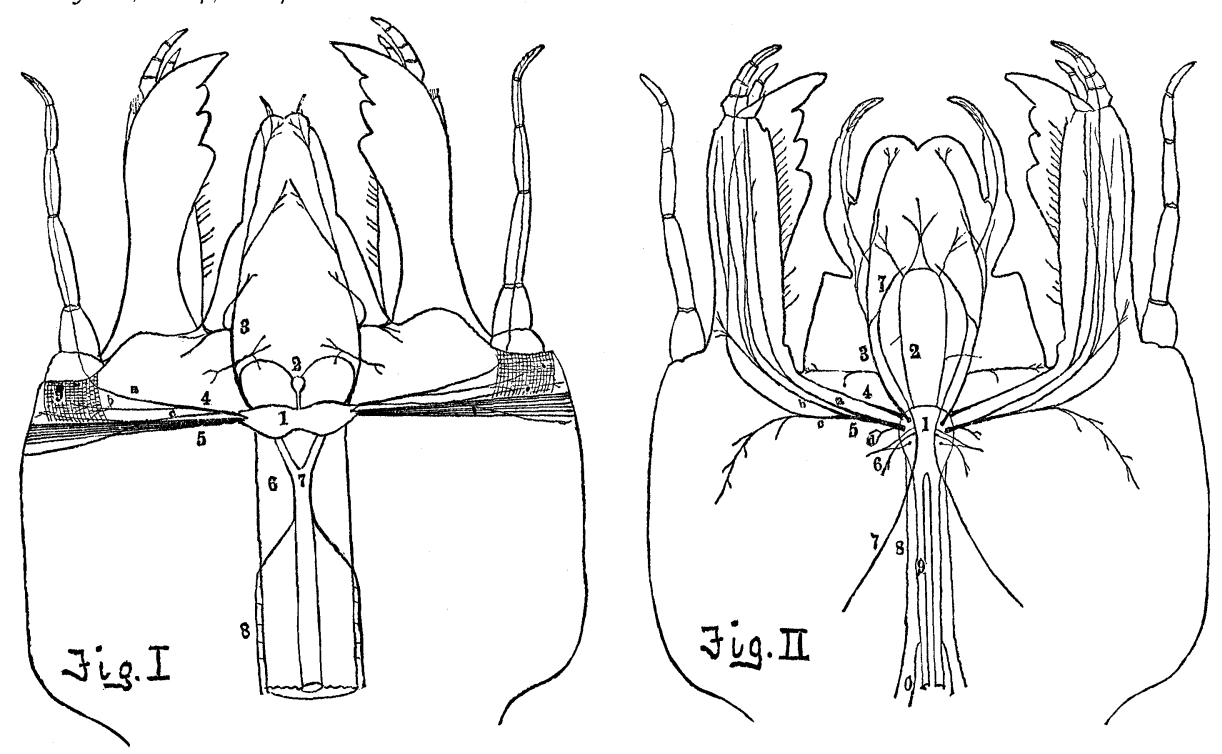

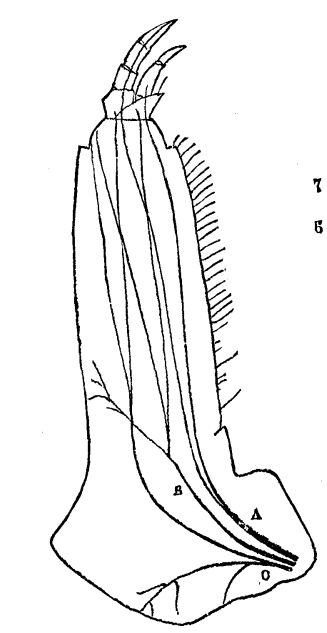

Jio. II
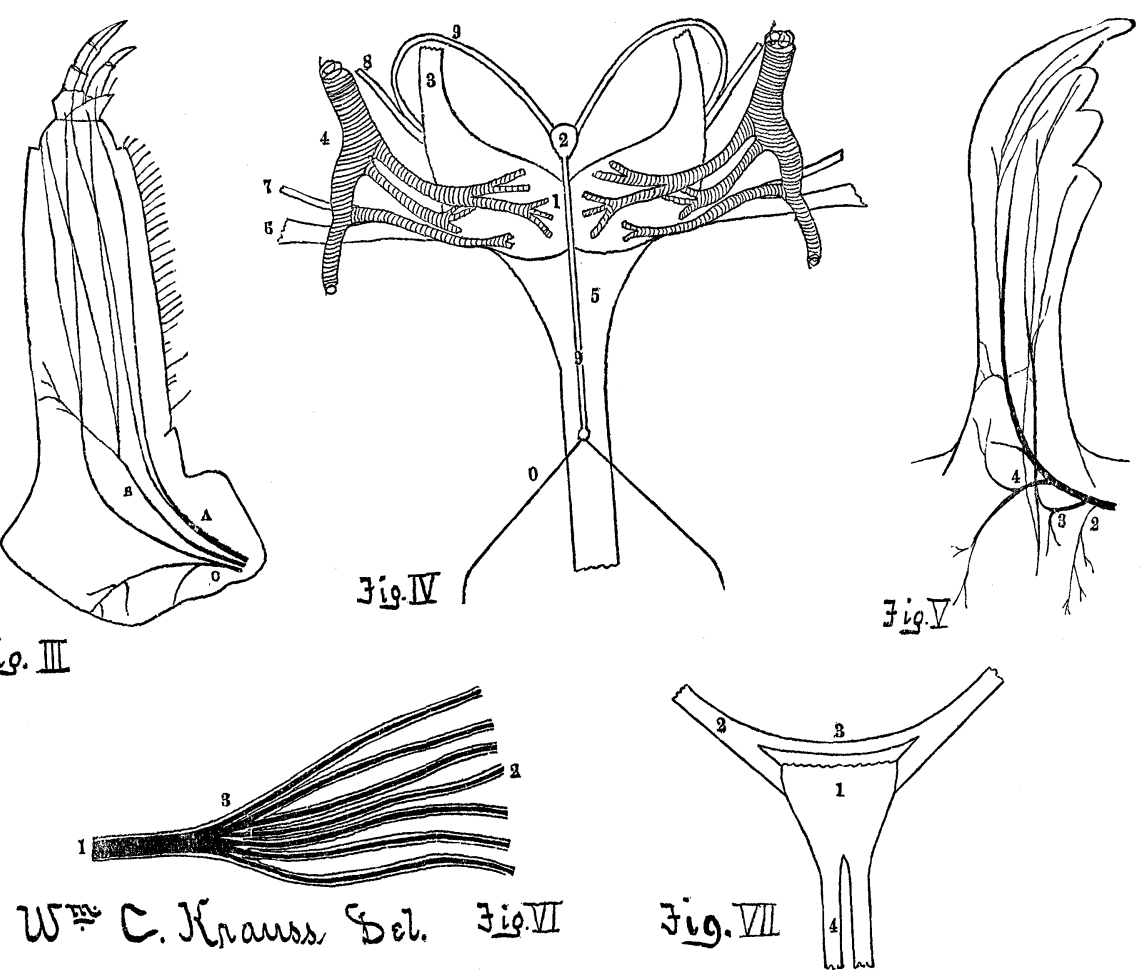

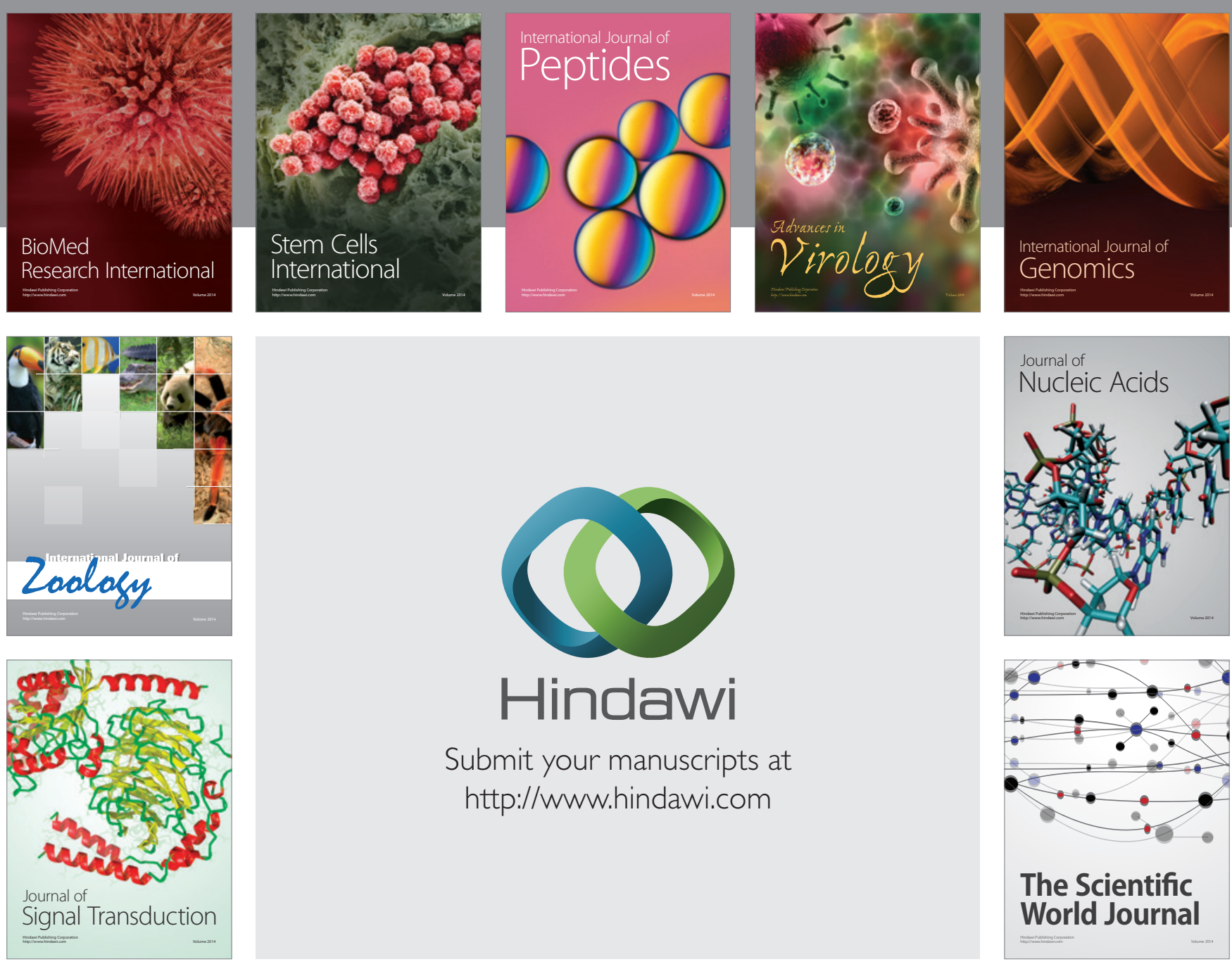

Submit your manuscripts at

http://www.hindawi.com
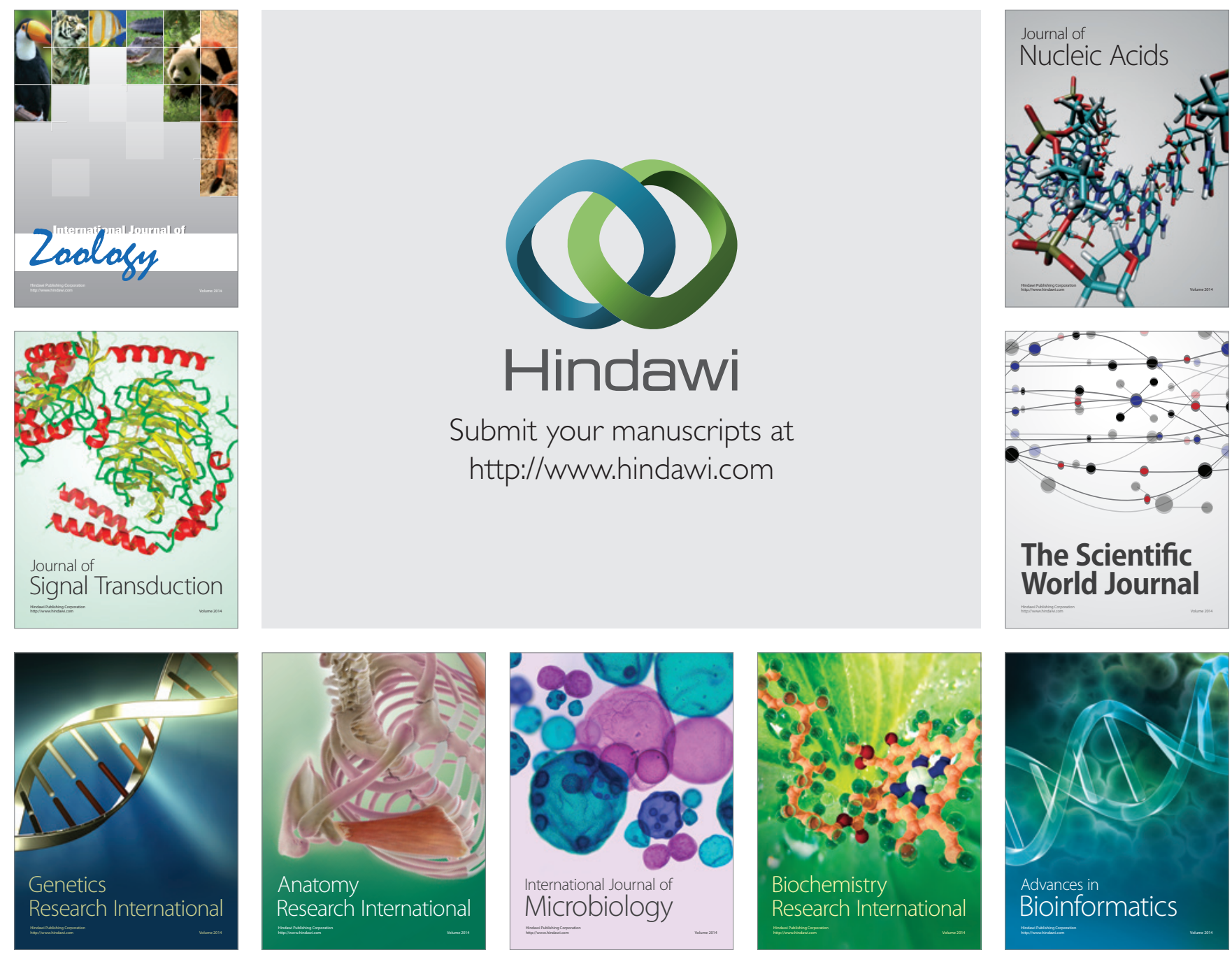

The Scientific World Journal
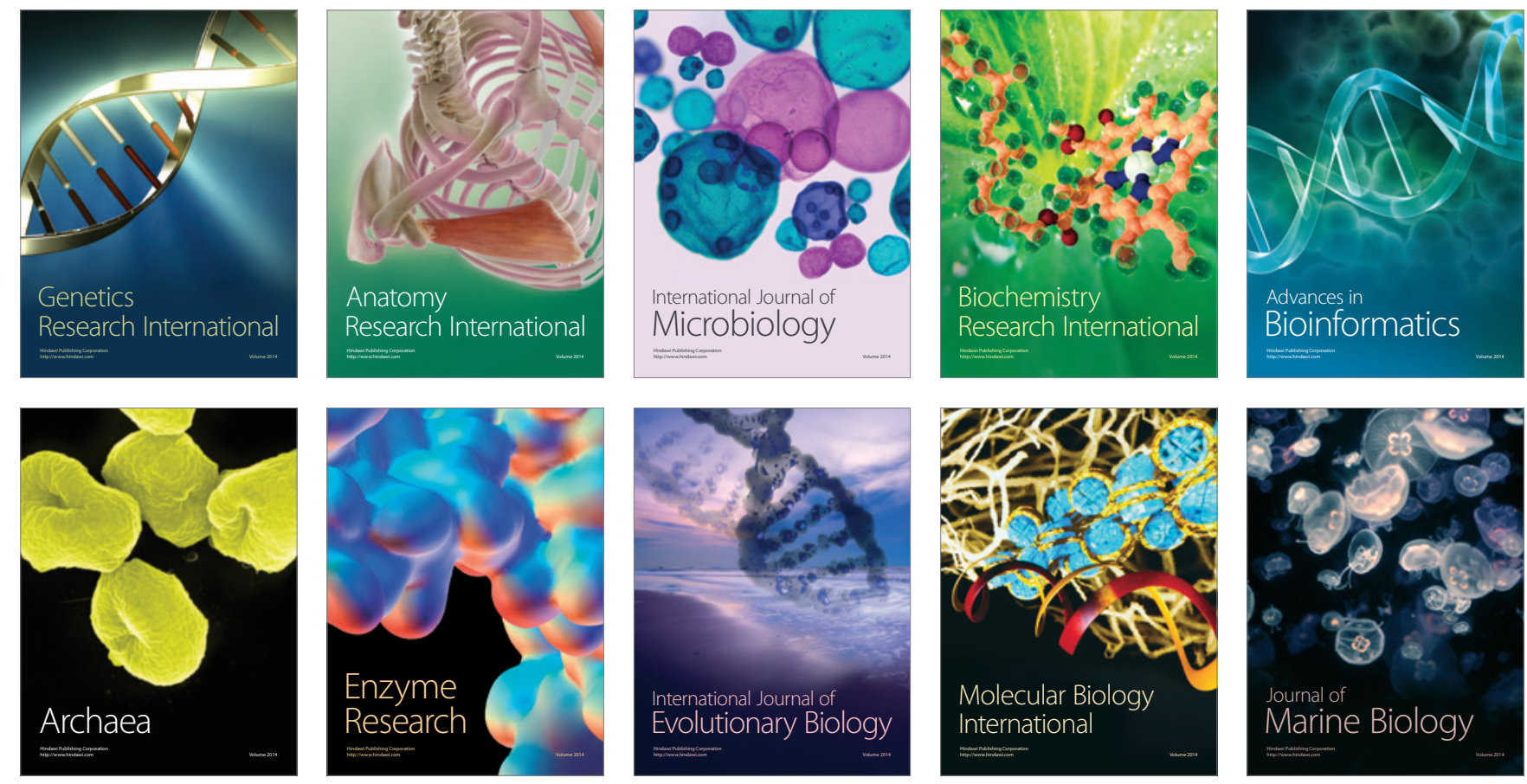